\title{
A Study of Cardiac Profile in Patients with Snake Envenomation and Its Complications
}

\author{
Ramakrishna C. D. , Placid Sebastian Kanattu \\ Department of Cardiology, Pariyaram Medical College, Kannur, India \\ Email: *drcdram@yahoo.com
}

How to cite this paper: Ramakrishna C.D. and Kanattu, P.S. (2017) A Study of Cardiac Profile in Patients with Snake Envenomation and Its Complications. International Journal of Clinical Medicine, 8, 167-177.

https://doi.org/10.4236/ijcm.2017.83017

Received: January 17, 2017

Accepted: March 28, 2017

Published: March 31, 2017

Copyright ( 92017 by authors and Scientific Research Publishing Inc. This work is licensed under the Creative Commons Attribution International License (CC BY 4.0).

http://creativecommons.org/licenses/by/4.0/ (c) (i) Open Access

\begin{abstract}
Background: Snake bite is a common and frequently devastating environmental and occupational disease, especially in rural areas of tropical developing countries. The present study was undertaken to evaluate the effect on cardiac profile in patients with snake envenomation and its complications. Methods: A total of 200 patients with snake envenomation were enrolled in this study excluding patients having history of any cardiovascular disease, renal disease, coagulopathy, liver disease, neuromuscular disease and those cases who bitten by non-poisonous snakes. All patients underwent physical examination, laboratory, Electrocardiogram (ECG), X-ray of chest and echocardiogram investigations. Results: A total of 200 cases had envenomation having 116 (58\%) of male subjects. Most common local signs were edema 187 (93.5\%), tenderness 141 (70.5\%), skin necrosis 81 (40.5\%) and blistering 12 (6\%). Severity of local envenomation was graded into mild 66 (33\%), moderate $120(60 \%)$ and severe $14(7 \%)$ cases. Systemic manifestations were present in 83 patients of venomous bites. It includes that majorly 53 (26.5\%) cases had vomiting, $44(22 \%)$ cases had abdominal pain and $9(4.5 \%)$ cases of hypotension. ECG manifestation showed 27 (13.5\%), 6 (3\%) and 1 (0.5\%) patients had sinus tachycardia, sinus bradycardia and ventricular tachycardia respectively. While, 9 (4.5\%) cases had $\mathrm{T}$ inversion alone in precordial leads. Mortality (3\%) was observed in intracranial bleed, neurotoxicity and capillary leak syndrome. However, cardiovascular involvement was not responsible for mortality in any cases. Conclusion: In conclusion, ventricular tachycardia is one of the manifestations of snake envenomation. Moreover, sinus tachycardia is common cardiovascular sign which may not be due to cardiac causes. Mortality results conclude that, cardiovascular involvement could not be responsible for mortality in snake envenomation.
\end{abstract}




\section{Keywords}

Snake Envenomation, Cardiac Complications, Sinus Tachycardia

\section{Introduction}

Snake bite is one of the major public health problems especially in tropical and subtropical countries. Snake bite is a common medical emergency encountered in the tropics and an estimated 35,000 - 50,000 people die of snake every year in India. Approximately $15 \%$ of 3000 species of snakes found worldwide are considered to be dangerous to humans. Among those species 52 poisonous species found in India, majority of bites and consequent mortality is attributable to 5 species viz. Ophiophagus hannah (king cobra), Naja naja (common cobra), Daboia ruselli (Rossell's viper), Bungarus caeruleus (krait) and Echis carinatae (saw-scaled viper). In Kerala, around 104 species are known, of which 37 are poisonous [1] [2] [3].

Snake venom is probably the oldest known poison to mankind and has been described in oldest medical books and myths. The snake venom contains many enzymes like digestive hydrolases, hyaluronidase, and activators or inactivators of physiological processes which include L-amino acid oxidase, phosphomono and diesterase, 5'-nucleotidase, DNAase, NAD-Nucleosidase, phospholipase A2, and peptidases. Also contains non enzymatic proteins and polypeptides. Among non enzymatic proteins, hemorrhagins, neurotoxins and cardiotoxins are important. Hemorrhagins are present mainly in Echis carinatus. Haemorrhage, shock and acute renal failure are the main causes of death in cases of elapide bite [4] [5]. Cardiotoxicity is also seen in many cases dying of severe viper bite. This may occur in the form of sudden hypotension, cardiac arrhythmia, myocardial infarction and changes in the electrocardiogram mainly of ST segment and $\mathrm{T}$ wave. Many cases of myocardial infarction following snake bite have seen reported [6] [7]. Coronary angiogram showed normal coronaries except in case where segmental contraction of coronaries was present. A case of second degree atrioventricular block has been reported [8]. In addition to this there may be pulmonary edema and alteration in enzymes like serum aspartate (SGOT) and creatine phosphokinase [5].

Mechanism of cardiotoxicity includes direct toxic effect on the myocardium, coagulation abnormalities and vasopasm induced by hemorrhagins or endothelins contained in the venom of some snakes [9]. Causes of hypotension and shock include hypovolemia, vasodilatation, and myocardial dysfunction. Moreover, bradykinin prolongs hypotensive effect by inactivating the peptidyl dipeptisase responsible both for destroying and for converting angiotensin I to angiotension II. This observation led to the synthesis of angiotensin-converting enzyme inhibitors (ACEI). Bradykinin-potentiating and ACE-inhibiting peptides have also been found in a number of other crotaline venoms [10] [11]. So far, least work has been done in India on complications and cardiotoxicity profile 
following poisonous snake bite. Therefore, present study was undertaken to find out the effect on cardiac profile and complications in the victims of snake envenomation.

\section{Methods}

\subsection{Patient Population and Study Design}

The prospective study was conducted in 200 patients of snake envenomation. Snake bite victims admitted to Government Medical College, Kottayam, Kerala, India from May 2005 to August 2006 were included in this study. Those patients had definite evidence (sign and symptoms) of snake envenomation were enrolled. While, those patients having history of any cardiovascular disease, renal disease, coaglulopathy, liver disease and liver muscular disease were excluded from this study. In addition, those cases who bitten by non-poisonous snakes were also excluded. All recruitments were conducted after obtaining informed written consent who qualifies the selection criteria.

All patients underwent physical examination, routine and specific laboratory investigation pertaining to snake envenomation. Moreover, specific cardiac profile determined by 12 lead Electrocardiogram (ECG), X-ray of chest and echocardiogram in all patients. Severity of bite was classified according to criteria suggested by Ramming with some modification by Saini et al. (1984) [12]. The details severity based classification depicted in Table 1 . The treatment was given as per WHO guidelines. The initial dose of polyspecific antisnake venom was given as $100 \mathrm{cc}$ without any change in dose for adults or children. Secondary dose can be given with 20 to $50 \mathrm{cc}$ at interval of $2-6 \mathrm{~h}$. Patients were continuously monitored for the development of any complication and were managed accordingly.

All investigations were conducted in conformity with ethical principles of research and according to guideline of declaration of Helsinki and approved by the ethical review board of the institution.

Table 1. Scoring classification based on severity of sign and symptoms in patients of snake envenomation.

\begin{tabular}{|c|c|c|c|}
\hline & Local & Systemic & Coagulation \\
\hline Minimal & $\begin{array}{l}\text { Swelling, erythema or } \\
\text { ecchymoses confined to site of bite }\end{array}$ & No coagulation signs or symptoms & $\begin{array}{l}\text { No coagulation abnormalities or other } \\
\text { important laboratory abnormalities }\end{array}$ \\
\hline Moderate & $\begin{array}{l}\text { Progress of swelling, } \\
\text { erythema or } \\
\text { ecchymosis beyond } \\
\text { the site of bite }\end{array}$ & $\begin{array}{l}\text { Non life threatening signs and } \\
\text { symptoms (Nausea, vomiting, } \\
\text { perioral paraesthesia, } \\
\text { myokymia \& mild hypotension) }\end{array}$ & $\begin{array}{l}\text { Mildly abnormal coagulation profile, } \\
\text { clinically significant bleeding and } \\
\text { mild abnormalities on other tests }\end{array}$ \\
\hline Severe & $\begin{array}{l}\text { Rapid swelling, erythema or } \\
\text { ecchymosis involving the } \\
\text { entire body part }\end{array}$ & $\begin{array}{l}\text { Markedly severe signs and symptoms } \\
\text { (hypotension-SBP }<90 \mathrm{mmHg} \text {, altered } \\
\text { sensorium, tachycardia, tachypnoe } \\
\text { and respiratory distress) }\end{array}$ & $\begin{array}{l}\text { Markedly abnormal coagulation profile } \\
\text { with evidence of bleeding or threat } \\
\text { of spontaneous hemorrhage, } \\
\text { (unmeasurable INR, } \\
\text { a PTT \& fibrinogen and severe } \\
\text { thrombocytopenia }<20,000 / \mathrm{cmm} \text { ) }\end{array}$ \\
\hline
\end{tabular}




\subsection{Statistical Analysis}

Patient baseline characteristics and procedural data were presented as frequency and percentages. In case of normal distribution, data presented as mean \pm SD while non-normal distribution data were presented as median (interquartile ranges).

\section{Results}

\subsection{Participant's Basic and Demographic Characteristics}

A total of 586 patients with suspected snake bites admitted to Pariyaram Medical College, Kannur, Kerala during study period. Out of these 586 patients, 200 cases had envenomation having $58 \%$ of male subjects. The age group most affected was 31 - 50 years (52\%). Majority (76.6\%) of cases of snake bite came to the hospital within 24 hours of bite while $40 \%$ reported within the first 12 hours. Venomous bite occurred in $93 \%$ of subject outdoor whereas, $7 \%$ patients were victim of indoor bites. Accidental bites occurs to $98.5 \%$ patients and rest $1.5 \%$ are snake charmers (occupation bites).In addition, site of bite at lower limb (81\%) is much more than upper limb (19\%).Whereas, no bites were observed over face or other part of body. All baseline characteristics of envenomated patients are depicted in Table 2.

Table 2. Baseline characteristics of envenomated patients.

\begin{tabular}{|c|c|}
\hline \multicolumn{2}{|c|}{ Variable } \\
\hline Total number of subjects, $\mathrm{n}$ & 200 \\
\hline Female, n (\%) & $84(42 \%)$ \\
\hline Age, median & Median $40(4-60)$ \\
\hline \multicolumn{2}{|c|}{ Location and type of Bite } \\
\hline Outdoor bites, n (\%) & $186(93 \%)$ \\
\hline Indoor bites, n (\%) & $14(7 \%)$ \\
\hline Accidental bites, n (\%) & $197(98.5 \%)$ \\
\hline Occupational (snake charmer) bites, n (\%) & $3(1.5 \%)$ \\
\hline \multicolumn{2}{|c|}{ Site of Bite } \\
\hline Lower limb, n (\%) & $162(81 \%)$ \\
\hline Upper limb, n (\%) & $38(19 \%)$ \\
\hline Rest of Body, n (\%) & $0(0 \%)$ \\
\hline \multicolumn{2}{|c|}{ Type of snakes } \\
\hline Viper, n (\%) & $65(32.5 \%)$ \\
\hline Cobra, n (\%) & $3(1.5 \%)$ \\
\hline Krait, n (\%) & $1(0.5 \%)$ \\
\hline Unknown, n (\%) & $131(65.5 \%)$ \\
\hline
\end{tabular}




\subsection{Clinical Manifestations}

\section{Local envenomation: signs and severity}

Fang mark was present in 107 cases which constituted about 53.5\% of venomous bites and 93 patients had no definite fang mark. Most common local sign was edema (93.5\%), tenderness (70.5\%), skin necrosis (40.5\%) and blistering (6\%). Severity of local envenomation was assessed by presence and extends of local edema which graded into mild (33\%), moderate (60\%) and severe (7\%) cases.

\section{Systemic manifestation:}

Systemic manifestations were present in 83 patients of venomous bites. It includes majorly 53 cases had vomiting, 44 cases had abdominal pain and 9 cases of hypotension. Moreover, one patient suffered with cardiac arrhythmia. The patient presented with a sustained monomorphic ventricular tachycardia (VT) at the rate of $180 /$ minute but did not have hypotension treated with i.v. amiodarone and not require cardioversion. Echocardiogram was normal with left ventricular function. It may be incidental cardiac arrhythmia or complication of snake envenomation but seen only in $0.5 \%$ of patients. Details systemic manifestation is depicted in Table 3.

Table 3. Clinical course of envenomated patients.

\begin{tabular}{|c|c|}
\hline Variable & \\
\hline \multicolumn{2}{|c|}{ Local Signs } \\
\hline Definite fang mark, n (\%) & $107(53.5 \%)$ \\
\hline Undefinite fang mark, $\mathrm{n}(\%)$ & $93(46.5 \%)$ \\
\hline Edema, n (\%) & $187(93.5 \%)$ \\
\hline Tenderness, n (\%) & $141(70.5 \%)$ \\
\hline Skin necrosis, n (\%) & $81(40.5 \%)$ \\
\hline Blistering, $\mathrm{n}(\%)$ & $12(6 \%)$ \\
\hline \multicolumn{2}{|c|}{ Severity of Envenomation } \\
\hline Mild, n (\%) & $66(33 \%)$ \\
\hline Moderate, n (\%) & $120(60 \%)$ \\
\hline Severe, $\mathrm{n}(\%)$ & $14(7 \%)$ \\
\hline \multicolumn{2}{|c|}{ Systemic manifestation } \\
\hline Vomiting, n (\%) & $53(26.5 \%)$ \\
\hline Abdominal Pain, n (\%) & $44(22 \%)$ \\
\hline Oliguria/anuria, n (\%) & $14(7 \%)$ \\
\hline Hypotension, n (\%) & $9(4.5 \%)$ \\
\hline Bleeding manifestation, $\mathrm{n}(\%)$ & $8(4 \%)$ \\
\hline Neurological symptoms, n (\%) & $6(3 \%)$ \\
\hline Presyncope/syncope, n (\%) & $4(2 \%)$ \\
\hline Cardiac arrhythmia, n (\%) & $1(0.5 \%)$ \\
\hline
\end{tabular}




\subsection{Laboratory Investigations}

Basic blood investigation were done along with bedside monitoring of clotting time, coagulation parameter like prothrombin time and activated partial thromboplastin time (PTT). Results suggest that, 127 patients have clotting time above the cut off value i.e. 20 minutes. Moreover, 104 patients showed cut off time greater than 10 second for PTT. Regarding low platelet count, 15 patients out of 76 patients $(19 \%)$ had severe thrombocytopenia $(<50,000)$ requiring platelet transfusion. Routine and other specific laboratory investigation were depicted in Table 4.

\subsection{Electrocardiogram Examinations}

ECG manifestation showed 27 cases had sinus tachycardia, 6 patients had sinus bradycardia. While 9 cases had $\mathrm{T}$ inversion alone in precordial leads. Detail of changes were observed in the ECG were represented in Figure 1.

Table 4. Initial laboratory findings of snake envenomated patients.

\begin{tabular}{cccc}
\hline Parameters & Cut of Value & \multicolumn{2}{c}{ Number of patients } \\
\cline { 2 - 3 } Hemoglobin & $>13.5 \mathrm{~g} / \mathrm{dl}$ in males & Normal & Abnormal \\
\hline Total leukocyte count & $>12 \mathrm{~g} / \mathrm{dl}$ in females & 142 & 58 \\
Platelet count & $<11,000 / \mathrm{cmm}$ & 140 \\
Blood urea & $>100,000 / \mathrm{cmm}$ & 124 & 51 \\
Serum creatinine & $<40 \mathrm{mg} / \mathrm{dl}$ & 149 & 51 \\
Clotting time & $<1.4 \mathrm{mg} / \mathrm{dl}$ & 149 & 127 \\
Prothombin time & $>20 \mathrm{minutes}$ & 73 & 126 \\
Activated PTT time & $>15$ seconds & 74 & 104 \\
\hline
\end{tabular}

PTT: Partial thromboplastin time.

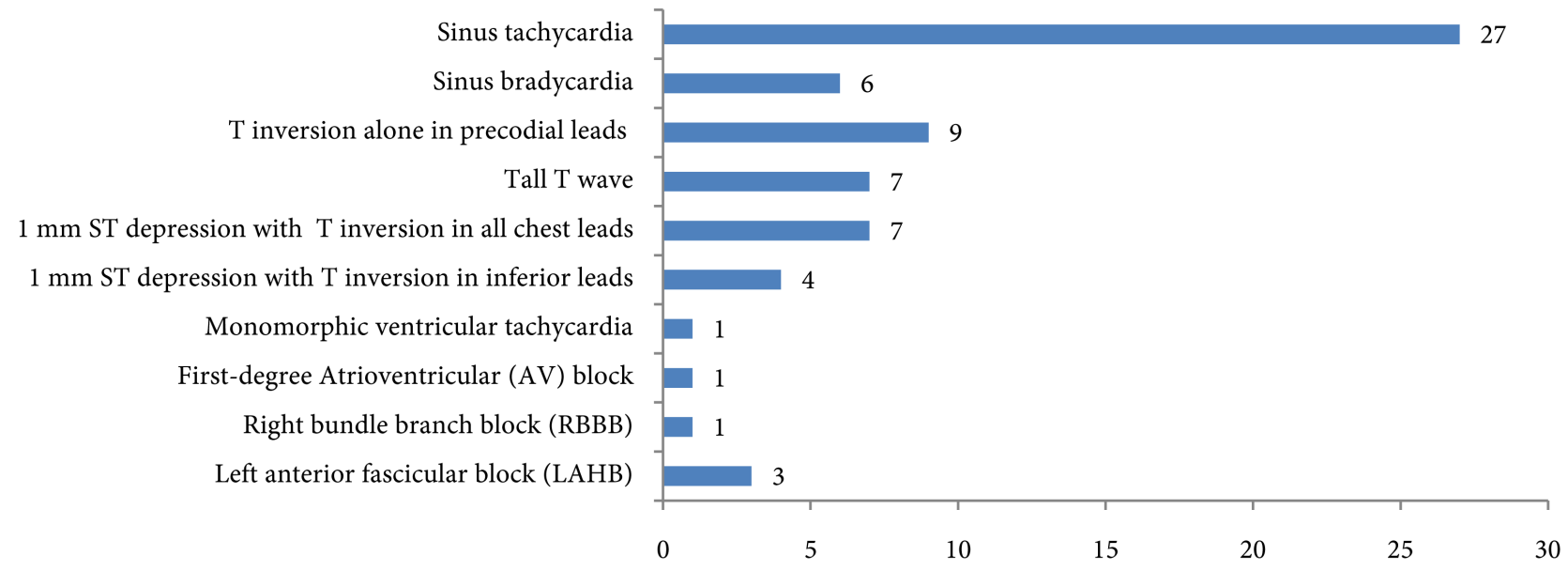

Figure 1. Changes observed during electrocardiogram examination of snake envenomated patients. 


\subsection{Echocardiogram Investigation}

Echocardiographic finding were within normal limit in all patients except 3 patients who had asymmetrical septal hypertrophy as an incidental finding. Patients with ventricular tachycardia had good ventricular function.

\subsection{Complications}

A total of 79 patients had represented with at least single complication. Table 5 represents the most common complications were acute renal failure in $51 \mathrm{pa}-$ tients and 39 cases of Intra vascular haemolysis. Compartment syndrome, secondary infection and unexplained hypotension were observed in $4(2 \%), 5$ $(2.5 \%)$ and 8 (4\%) patients. One case had ventricular tachycardia with no risk for coronary artery disease, which is reverted to normal sinus rhythm with direct current (DC) cardioversion followed by anti snake venom. This patient with ventricular tachycardia had good ventricular function.

\subsection{Laboratory Investigations}

\section{Mortality}

Mortality was observed in 6 cases of total venomous bites patients (Figure 2). Mortality was observed in intracranial bleed, neurotoxicity and capillary leak syndrome. Clinically, neurotoxicity was assessed by testing for muscle power and for adequacy of ventilatory function. However, cardiovascular involvement was not responsible for mortality in any cases.

\section{Discussion}

This study on the profile of cardiovascular complications due to snake bite was carried out with a view to observe the changes in cardiovascular system. A total of 200 subjects with venomous bites were studied. There were 116 males and 84 females with ratio of 1.4:1.

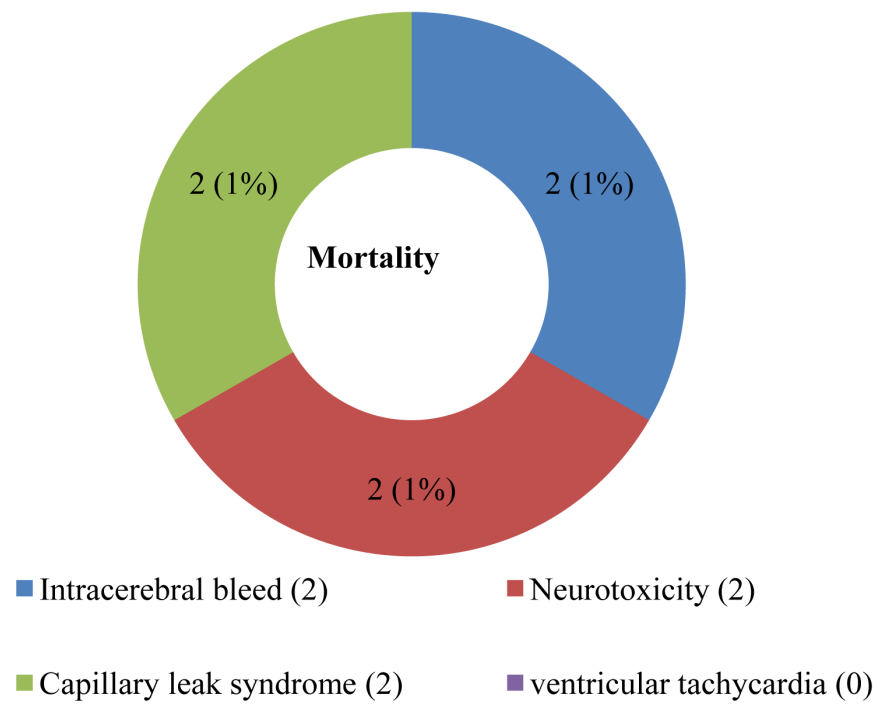

Figure 2. The effect on mortality in snake envenomated patients. 
Table 5. Different complications in snake envenomated patients.

\begin{tabular}{cc}
\hline Complications & Patients \\
\hline Acute renal failure & $51(25.5 \%)$ \\
Intra vascular haemolysis & $39(19.5 \%)$ \\
Unexplained hypotension & $8(4 \%)$ \\
Secondary infection & $5(2.5 \%)$ \\
Compartment syndrome & $4(2.0 \%)$ \\
Intra cerebral bleed & $4(2.0 \%)$ \\
Neurotoxicity & $2(1.0 \%)$ \\
Ventricular tachycardia & $1(0.5 \%)$ \\
Capillary leak syndrome & $2(1.0 \%)$ \\
\hline
\end{tabular}

Systemic manifestations were present in 83 patients $(41.5 \%$ of venomous bites). Most common manifestation noted was vomiting which was present in 26.5\% patients. Prolonged clotting time was the commonest manifestation of systemic toxicity in haemotoxic snake bites. In addition, Pain abdomen was present in $22 \%$ and $7 \%$ patients had renal manifestation in the form of oliguria/ anuria, hypotension was noted in $4.5 \%$ of venomous bites. Moreover, $2 \%$ patients with presyncope/syncope and 4 cases presented in a coma state due to intra cerebral bleed secondary to haemotoxic envenomation. One patient presented with palpitation due to ventricular tachycardia which reverted to normal with DC shock followed by antisnake venom administration. Nayak et al. (1990) showed $25 \%$ of cardiotoxicity among viperine bite [3]. In our study, cardiac involvement as evidenced by electrocardiographic changes which reverted to normal was present in $31.5 \%$ of patients. Out of this only one patient had serious complication like ventricular tachycardia. Most common cardiac manifestation was sinus tachycardia which was present in 27 patients. Even though there are earlier reports of myocardial infarction [7] [13], none of our patients had ST elevation in electrocardiogram suggestive myocardial infarction. Eleven patients had ST depression in either anterior or inferior leads which might be due to coronary artery involvement or myocartitis. None of our patients had chest pain even though ECG showed changes like ST depression. Previous reported cardiotoxicity in $7 \%$ cases or elapide bite and none in viper bite case [14]. None of the patients in our study had features of pulmonary edema. Features of peripheral circulatory failure were present in $4 \%$ patients who responded to antisnake venom, volume replacement and inotropes.

In the present study, heart rate disturbance was present in 16.5 percent out of which $13.5 \%$ had tachycardia and $3 \%$ had bradycardia. This finding is almost reverse of the observation of Reid et al. (1975) [5]. In patients who had tachycardia without other ECG changes, heart rate returned to normal in 12 - 20 hours. Tachycardia was probably because of shock, fever or acute blood loss. However, bradycardia may occur due to direct depressant action of snake venom over sinoatrial node. Rhythm disturbance in the form of ventricular tachycardia was 
seen in 1 patient of our series. Ventricular tachycardia as a presentation of snake envenomation has been reported earlier [15].

Eight patients had unexplained hypotension (4\%) and none of the patient had hypertension. These observations are similar to those of previous literature. Hypertension has noted in patients with snake bite, which was probably psychogenic in origin which is a well known factor in producing hypertension. The possible mechanisms responsible for hypotension could be excessive blood loss as bleeding tendency was seen in $63 \%$ patients in our study and vasovagal syncope after snake bite or bradykinin induced vasodilation [16]. None of the patient had pulmonary edema. However, previously pulmonary edema was reported in $6.6 \%$ of snake envenomated patients by Nayak et al. (1990) [3].

Our results reflect, abnormality in ECG was found in $31.5 \%$ patients. Most of these appear to be due to sinus tachycardia, which may be related to the stress of illness or being hospitalized, and may make the rate of "abnormality" seem high. However, this incidence differs from the reported observations of Reid who reported an abnormal ECG in $2 \%$ cases [5]. Ischaemic changes like ST depression were seen in $5.5 \%$ cases which reverted to normal within 3 - 4 days. These ECG changes can be explained by two possibilities; one is that changes in ST-T segment because of thrombosis or sub-intimal haemorrhage in coronary vessels. Snake venom causes disseminated intravascular coagulation which can lead to thrombosis or sub-intimal haemorrhage in coronary arteries and produces ECG changes. Another possibility may be direct toxic effect of venom on heart which may likely give an explanation for sinus bradycardia, arrhythmias and atrioventricular block [17].

In addition, mortality was $3 \%$ which is varies from previous literature, as $10 \%$ and $1.96 \%$ mortality were observed by Nayak et al. (1990) and Bhat et al. (1974) [3] [18]. All those patients had severe envenomation and late hospitalization. Also, they were in shock, and some may had massive bleeding. Cardiovascular complication was not responsible for mortality in any of the cases.

\section{Limitations of the Study}

Being a tertiary care center, study may not be real reflection of the original magnitude of the problem in the community. Moreover, majority of the study groups were haemotoxic bites and the number of elapid bites was very small in the study group. However, there were no long term follow up of the patients who showed ECG abnormalities.

\section{Conclusion}

Overall analysis of results suggests that, cardiac involvement is uncommon in snake envenomation. As occurrence of sinus tachycardia in snake envenomation was most likely due to non-cardiac causes. Mortality results suggest that, cardiovascular involvement may not be responsible for mortality in snake envenomation. 


\section{References}

[1] Kasturiratne, A., Wickremasinghe, A.R., de Silva, N., Gunawardena, N.K., Pathmeswaran, A., Premaratna, R., Savioli, L., Lalloo, D.G. and de Silva, H.J. (2008) The Global Burden of Snakebite: A Literature Analysis and Modelling Based on Regional Estimates of Envenoming and Deaths. PLoS medicine, 5, e218. https://doi.org/10.1371/journal.pmed.0050218

[2] Kang, S., Moon, J. and Chun, B. (2016) Does the Traditional Snakebite Severity Score Correctly Classify Envenomated Patients? Clinical and experimental emergency medicine, 3, 34-40.

[3] Nayak, K.C., Jain, A.K., Sharda, D.P. and Mishra, S.N. (1990) Profile of Cardiac Complications of Snake Bite. Indian Heart Journal, 42, 185-188.

[4] Cherifi, F. and Laraba-Djebari, F. (2013) Isolated Biomolecules of Pharmacological Interest in Hemostasis from Cerastes Cerastes Venom. The Journal of Venomous Animals and Toxins Including Tropical Diseases, 19, 11. https://doi.org/10.1186/1678-9199-19-11

[5] Reid, H.A. (1975) Bites and Stings in Travellers. Postgraduate Medical Journal, 51, 830-837. https://doi.org/10.1136/pgmj.51.602.830

[6] Brown, R. and Dewar, H.A. (1965) Heart Damage following Adder Bite in England. British Heart Journal, 27, 144-147. https://doi.org/10.1136/hrt.27.1.144

[7] Blondheim, D.S., Plich, M., Berman, M., Khair, G., Tzvig, L., Ezri, J. and Marmor, A.T. (1996) Acute Myocardial Infarction Complicating Viper Bite. The American Journal of Cardiology, 78, 492-493. https://doi.org/10.1016/S0002-9149(96)00347-5

[8] Moore, R.S. (1988) Second-Degree Heart Block Associated with Envenomation by Vipera Berus. Archives of Emergency Medicine, 5, 116-118. https://doi.org/10.1136/emj.5.2.116

[9] Maduwage, K. and Isbister, G.K. (2014) Current Treatment for Venom-Induced Consumption Coagulopathy Resulting from Snakebite. PLoS Neglected Tropical Diseases, 8, e3220. https://doi.org/10.1371/journal.pntd.0003220

[10] White, J. (2005) Snake Venoms and Coagulopathy. Toxicon: Official Journal of the International Society on Toxinology, 45, 951-967.

[11] Klauser, R.J., Robinson, C.J., Marinkovic, D.V. and Erdös, E.G. (1979) Inhibition of Human Peptidyl Dipeptidase (Angiotensin I Converting Enzyme: Kininase II) by Human Serum Albumin and Its Fragments. Hypertension, 1, 281-286.

https://doi.org/10.1161/01.HYP.1.3.281

[12] Saini, R.K., Sharma, S., Singh, S. and Pathania, N.S. (1984) Snake Bite Poisoning: A Preliminary Report. The Journal of the Association of Physicians of India, 32, 195-197.

[13] Maheshwari, M. and Mittal, S.R. (2004) Acute Myocardial Infarction Complicating Snake Bite. The Journal of the Association of Physicians of India, 52, 63-64.

[14] Banerjee, R. and Siddiqui, Z. (1978) Epidemiological Study of Snake-Bite in India. Toxins: Animal, Plant and Microbial. 1st Edition, 439-446.

[15] Thewjitcharoen, Y. and Poopitaya, S. (2005) Ventricular Tachycardia, a Rare Manifestation of Russell's Viper Bite: Case Report. Journal of the Medical Association of Thailand = Chotmaihet thangphaet, 88, 1931-1933.

[16] Ahmed, S.M., Ahmed, M., Nadeem, A., Mahajan, J., Choudhary, A. and Pal, J. (2008) Emergency Treatment of a Snake Bite: Pearls from Literature. Journal of Emergencies, Trauma, and Shock, 1, 97-105. https://doi.org/10.4103/0974-2700.43190

[17] Chadha, J.S., Ashby, D.W. and Brown, J.O. (1968) Abnormal Electrodiogram after 
Adder Bite. British Heart Journal, 30, 138-140. https://doi.org/10.1136/hrt.30.1.138

[18] Bhat, R.N. (1974) Viperine Snake Bite Poisoning in Jammu. Journal of the Indian Medical Association, 63, 383-392.

Submit or recommend next manuscript to SCIRP and we will provide best service for you:

Accepting pre-submission inquiries through Email, Facebook, LinkedIn, Twitter, etc. A wide selection of journals (inclusive of 9 subjects, more than 200 journals)

Providing 24-hour high-quality service

User-friendly online submission system

Fair and swift peer-review system

Efficient typesetting and proofreading procedure

Display of the result of downloads and visits, as well as the number of cited articles Maximum dissemination of your research work

Submit your manuscript at: http://papersubmission.scirp.org/

Or contact ijcm@scirp.org 